\title{
Evidence for the Presence of Xenopsin-related Peptide(s) in the Gastric Mucosa of Mammals
}

\author{
Gerhard E. Feurle, Robert E. Carraway, Eckhard Rix, and Wolfgang Knauf \\ Medizinische Poliklinik, University of Heidelberg, Federal Republic of Germany; and Department of Physiology, \\ University of Massachusetts Medical Center, Worcester, Massachusetts 01605
}

\begin{abstract}
Using immunohistochemistry and radioimmunoassay, substance(s) related to the amphibian octapeptide xenopsin (XP) were demonstrated in the gastric mucosa of humans and dogs. Immunohistochemistry localized XP-immunoreactive epithelial cells in the gastric antral mucosa. The reaction was abolished by preabsorption of the antiserum with XP but not by neurotensin or other peptides. Immunoreactive XP (iXP) was found by radioimmunoassay in extracts of both the antrum and body of the stomach prepared with acid/acetone or acetic acid. A study of its distribution in the dog indicated that the level of iXP was highest in the stomach, lower in the pancreas and duodenum, and not measurable in the jejunoileum and colon. Gel chromatography on Sephadex G-25 indicated the presence of at least two forms of iXP, one larger and the other about the same size as XP. Reverse-phase high pressure liquid chromatography on $\mu$-Bondapak $\mathrm{C}$-18 yielded several peaks of iXP, one of which eluted at the position of synthetic XP. The results of immunochemical analyses using four different antisera towards XP were consistent with structures for canine iXPs that were closely related to XP only in their $\mathbf{C}$-terminal regions. These results suggest that mammalian counterparts to amphibian XP reside within endocrine cells of the gastric mucosa. It seems possible that these peptides function as gastrointestinal signals.
\end{abstract}

\section{Introduction}

Xenopsin (XP) ${ }^{1}$ is an octapeptide that shares certain structural and biological features with neurotensin $(\mathrm{NT})(1,2)$. Although $\mathrm{XP}$ initially became known as a peptide from amphibian skin and was found only in Xenopus laevis, recent studies by our group established its presence within the brain and gastrointestinal tissues of many amphibians (3). NT-related substances, apart from XP, were also demonstrated in these amphibian tissues, suggesting that XP was not the amphibian counterpart to mammalian NT but rather a member of a closely related family of peptides.

Address correspondence to Dr. Feurle, Medizinische Poliklinik, University of Heidelberg, Hospitalstr. 3, 6900 Heidelberg 1, FRG.

Received for publication 14 December 1984 and in revised form 8 March 1985

1. Abbreviations used in this paper: $\mathrm{B}$, bound radioactivity; $\mathbf{B}_{0}$, bound radioactivity of the antiserum; HPLC, high pressure liquid chromatography; iNT, immunoreactive NT; iXP, immunoreactive XP; NT, neurotensin; PAP, peroxidase-antiperoxidase; XP, xenopsin.

J. Clin. Invest.

(C) The American Society for Clinical Investigation, Inc.

0021-9738/85/07/0156/07 \$1.00

Volume 76 , July 1985 , 156-162
Although in many amphibians both XP-related and NTrelated peptides could be shown to exist in the same animal, the tissue distributions for the two sets of peptides differed (3). XP-related material was primarily found in the stomach, pancreas, and skin, while NT-related substances were present at higher concentrations in the lower small intestine and the brain.

The cooccurrence of XP- and NT-related peptides in amphibians led us to investigate the existence of counterparts to amphibian XP in the mammal. Here we report evidence, obtained by immunohistochemistry and radioimmunoassay (RIA), indicating the presence of XP-related peptides within epithelial cells of canine and human gastric mucosa. The substances present in gastric extracts were characterized immunochemically and chromatographically using multiple antisera towards synthetic XP and NT in conjunction with reverse-phase high pressure liquid chromatography (HPLC).

\section{Methods}

Tissues. Gastric antral biopsies taken during endoscopy of a young man with ulcer disease were fixed for $1 \mathrm{~h}$ by immersion in modified Bouin's solution (37\% formaldehyde containing $50 \%$ saturated picric acid solution in water and $0.25 \%$ glutaraldehyde) and then transferred to $70 \%$ ethanol.

Six bastard dogs were killed by intravenous injection of potassium chloride. The gastrointestinal tissues were removed and immediately placed on ice. Tissue samples of gastric mucosal and muscular layers, duodenum, jejunum, ileum, and pancreas of $\sim 5 \mathrm{~g}$ were dissected and either frozen on dry ice and then kept at $-20^{\circ} \mathrm{C}$ or prepared for immunohistochemistry as described above.

Immunohistochemistry. The tissue was dehydrated in ethanol and embedded in paraffin or Epon ${ }^{\oplus}$, respectively. Paraffin sections of 10 $\mu \mathrm{m}$ were deparaffinized and processed according to the peroxidaseantiperoxidase (PAP) technique using the various antisera in dilutions of 1:500-1:2,000 (for technical details see reference 4). Semithin Epon ${ }^{\otimes}$ sections $(0.3 \mu \mathrm{m})$, after the Epon ${ }^{\otimes}$ was removed, were incubated with the various antisera in dilutions of 1:500-1:1,000 and processed according to the PAP technique (for technical details see reference 5). Neu-6, the antiserum towards NT, has been previously described (6).

Specificity was tested by the use of nonimmune sera and preabsorbed antisera. Preabsorption was performed by incubating $500 \mu \mathrm{l}$ of the antiserum Xen-7 (diluted 1:500) with $2 \mu \mathrm{g}$ of either XP, NT, gastrin, somatostatin, glucagon, met-enkephalin, or leu-enkephalin, each of which was dissolved in $500 \mu \mathrm{l}$ phosphate buffer, and by incubating Xen-7 with phosphate buffer alone for $48 \mathrm{~h}$ at $4^{\circ} \mathrm{C}$.

Extraction. The tissue samples were extracted by two different techniques similar to the methods described earlier (7). Frozen tissue of $\sim 1 \mathrm{~g}$ was homogenized in 4 vol (weight per volume) of acid/ acetone ( 97 parts acetone and 3 parts $1 \mathrm{~N} \mathrm{HCl}$ ) using an Ultraturrax (Janke and Kunkel, Staufen, FRG). The homogenate was held at $4^{\circ} \mathrm{C}$ overnight, then centrifuged at $15,000 \mathrm{~g}$ for $30 \mathrm{~min}$. The supernatant was extracted three times by a fourfold volume of petroleum ether. The aqueous phase was dried under a stream of dry air.

Other frozen and weighed tissue samples were immersed in $10 \mathrm{vol}$ $2 \mathrm{~N}$ acetic acid, homogenized with the Ultraturrax, and centrifuged 30 
min at $15,000 \mathrm{~g}$. The pellet was reextracted in $5 \mathrm{vol} 2 \mathrm{~N}$ acetic acid and recentrifuged. Both supernatants were combined and lyophilized. The dried residues were kept at $-20^{\circ} \mathrm{C}$ until dissolved in buffer and subjected to RIA or chromatography.

Preparation of antisera. Synthetic XP was coupled to bovine serum albumin using glutaraldehyde, as previously described for other peptides (8). The conjugate was emulsified with complete Freund's adjuvant and injected into foot pads of albino rabbits. Each of six rabbits received $\sim 1 \mathrm{ml}$ of conjugate containing $0.5-1.0 \mathrm{mg} \mathrm{XP}$ and $1.3 \mathrm{mg}$ albumin. After repeated booster injections with $250 \mu \mathrm{g}$ conjugated peptide emulsified in incomplete Freund's adjuvant, four of the six animals were found to produce useful antisera with titers ranging from $1: 8,000$ to $1: 1,000,000$.

Iodination and RIA. Since XP lacks a tyrosine residue we initially employed iodinated NT as a tracer in the RIA. This was prepared as previously described, except that it was purified using HPLC (9). Iodinated NT could have been used with the Xen-6 antiserum; however, it did not bind well to the other antisera. For these, (3-[4OH-phenyl]-propionyl)-XP, a derivative of XP that could be iodinated, was prepared and purified as detailed below. Every 2-3 mo $10 \mu \mathrm{g}$ of this XP derivative was iodinated with $1.0 \mathrm{mCi}$ of ${ }^{125} \mathrm{I}$ using chloramine $T$, and the iodinated peptide was separated from the uniodinated material using HPLC. RIA was performed using a previously described procedure (3). Bound radioactivity (B) was determined using a 16-well $\gamma$-counter (Nuclear Enterprises, Scotland) with on-line computerized data analysis using a log-logit linearization program and also yielding $B /$ bound radioactivity of the antiserum $\left(B_{0}\right)$ for each sample (IN/US Service Corp., Fairfield, NJ). The displacement curves for extracts (Fig. 3 ) were obtained by plotting the computed $B / B_{0}$ for varying quantities of each sample on semi-log paper. The RIA for NT employed the Cterminal-directed antiserum $\mathrm{HC}-8$ (9) and the N-terminal-directed TG-1 (10). Antiserum HC-8 is known to react $100 \%$ with $\mathrm{NT}^{6-13}$ and $<0.01 \%$ with $\mathrm{NT}^{1-8}$, while antiserum TG-1 reacts $20 \%$ with $\mathrm{NT}^{1-8}$, $66 \%$ with $\mathrm{NT}^{1-11}$, and $<0.2 \%$ with $\mathrm{NT}^{6-13}$.

Preparation of peptides and derivatives. The $\mathrm{XP}^{2-8}$ fragment was prepared by treating $20 \mu \mathrm{g}$ synthetic XP with pyroglutamyl aminopep- tidase (Boehringer Mannheim Diagnostics, Inc., Houston, TX) in 100 $\mu l$ sodium phosphate buffer $(0.1 \mathrm{M}, \mathrm{pH} 7.8)$ overnight at $40^{\circ} \mathrm{C}$. The $\mathrm{XP}^{1-6}$ fragment was prepared by treating $20 \mu \mathrm{g}$ XP with $2 \mu \mathrm{g}$ carboxypeptidase A (Boehringer Mannheim Diagnostics, Inc.) in 100 $\mu l$ ammonium bicarbonate $(0.1 \mathrm{M}, \mathrm{pH} 8.0)$ for $10 \mathrm{~min}$ at $20^{\circ} \mathrm{C}$. The products were isolated using HPLC as described below.

The XP derivative for iodination was prepared by adding $100 \mu \mathrm{g}$ $\mathrm{XP}$ dissolved in $0.1 \mathrm{M}$ borate buffer (pH 8.8) to a glass tube containing $200 \mu \mathrm{g}$ of $\mathrm{N}$-succinimidyl-3-(4-OH-phenyl)-propionate (Pierce Chemical Co., Rockford, IL). After $15 \mathrm{~min}$ at $20^{\circ} \mathrm{C}$, the product was purified using HPLC as described below. The product was assumed to be derivatized only at the $\epsilon$-amino group of the lysine residue, which is the only free amino group in XP.

Chromatography. Gel filtration was performed as previously described using $0.2 \mathrm{M}$ acetic acid as eluant and a $200-\mathrm{ml}$ column $(1.6 \times 98 \mathrm{~cm})$ of Sephadex G-25. After the sample was applied, $53 \mathrm{ml}$ effluent was discarded and fractions of $2.4 \mathrm{ml}$ were collected. Reversephase HPLC was performed using a Waters system (Waters Associates, Millipore Corp., Milford, MA) as previously described (3). For examining tissue extracts, the column employed $(3.9 \mathrm{~mm} \times 30 \mathrm{~cm})$ was $\mu$ Bondapak C-18 equilibrated with $10 \mathrm{mM}$ sodium phosphate, $\mathrm{pH} 5.0$. Elution was performed at a flow rate of $1.5 \mathrm{ml} / \mathrm{min}$ using a linear gradient over $30 \mathrm{~min}$ to $30 \% \mathrm{CH}_{3} \mathrm{CN}$. Fractions $(0.75 \mathrm{ml})$ were collected at 0.5 -min intervals. For purification of the fragments of XP, the same column and buffers were used with a linear gradient to $50 \%$ $\mathrm{CH}_{3} \mathrm{CN}$ over $40 \mathrm{~min}$. XP eluted at $25 \mathrm{~min}, \mathrm{XP}^{2-8}$ at $24 \mathrm{~min}$, and $\mathrm{XP}^{1-6}$ at $15 \mathrm{~min}$. For the purification of $N-(p-\mathrm{OH}$-phenylpropionate)$\mathrm{XP}$ a $\mu$-Bondapak phenyl column was used with $0.1 \%$ trifluoroacetic acid and a linear gradient to $50 \% \mathrm{CH}_{3} \mathrm{CN}$ over $30 \mathrm{~min}$. XP eluted at $19 \mathrm{~min}$, the derivative at $25 \mathrm{~min}$.

\section{Results}

Immunohistochemistry. Immunohistochemistry with the Xen7 antiserum revealed numerous epithelial XP-immunoreactive

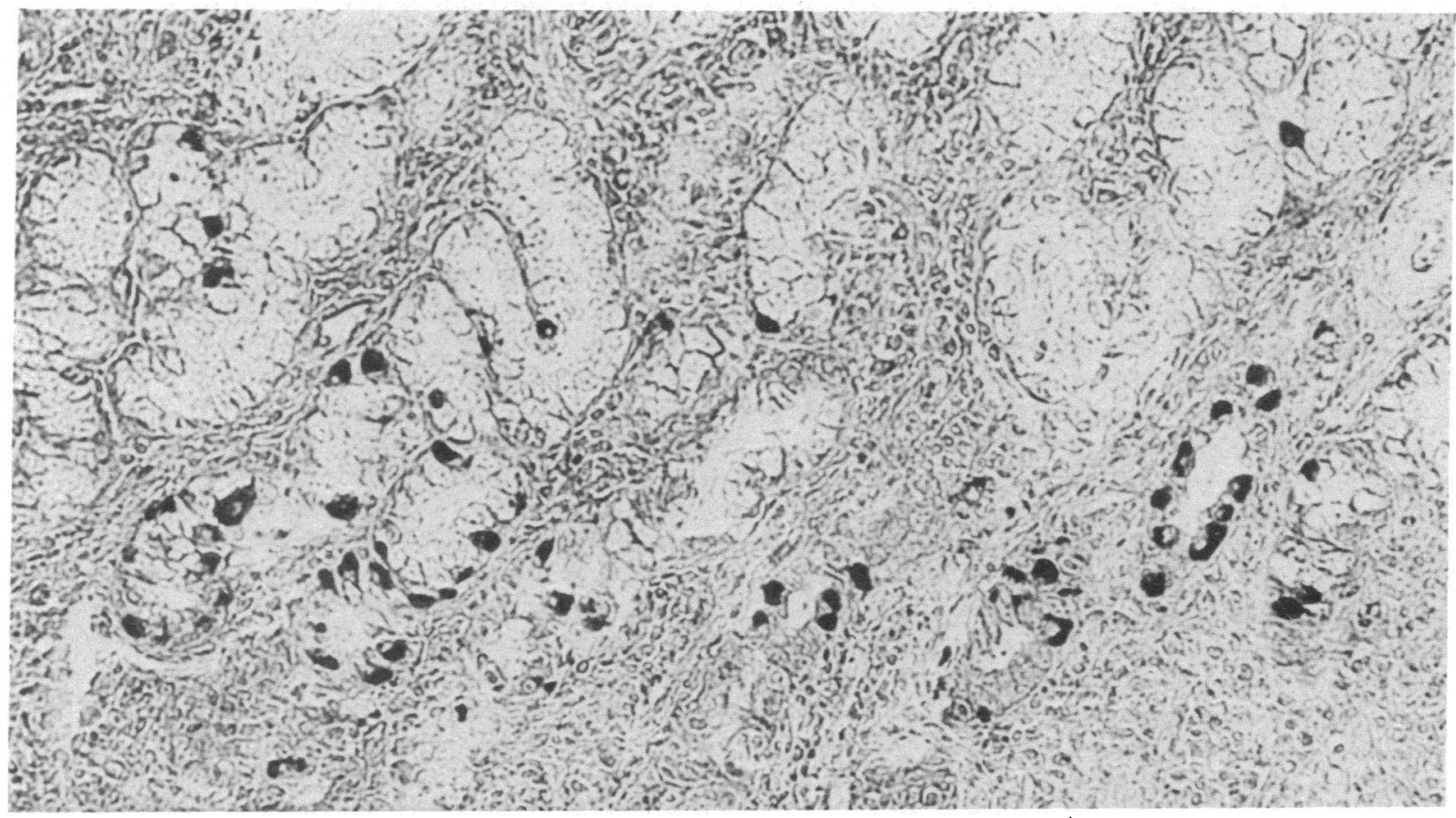

Figure 1. Immunohistochemistry with the PAP method and an XP antiserum (Xen-7) on a human gastric antral biopsy showing numerous positively stained cells $(\times 230)$. 


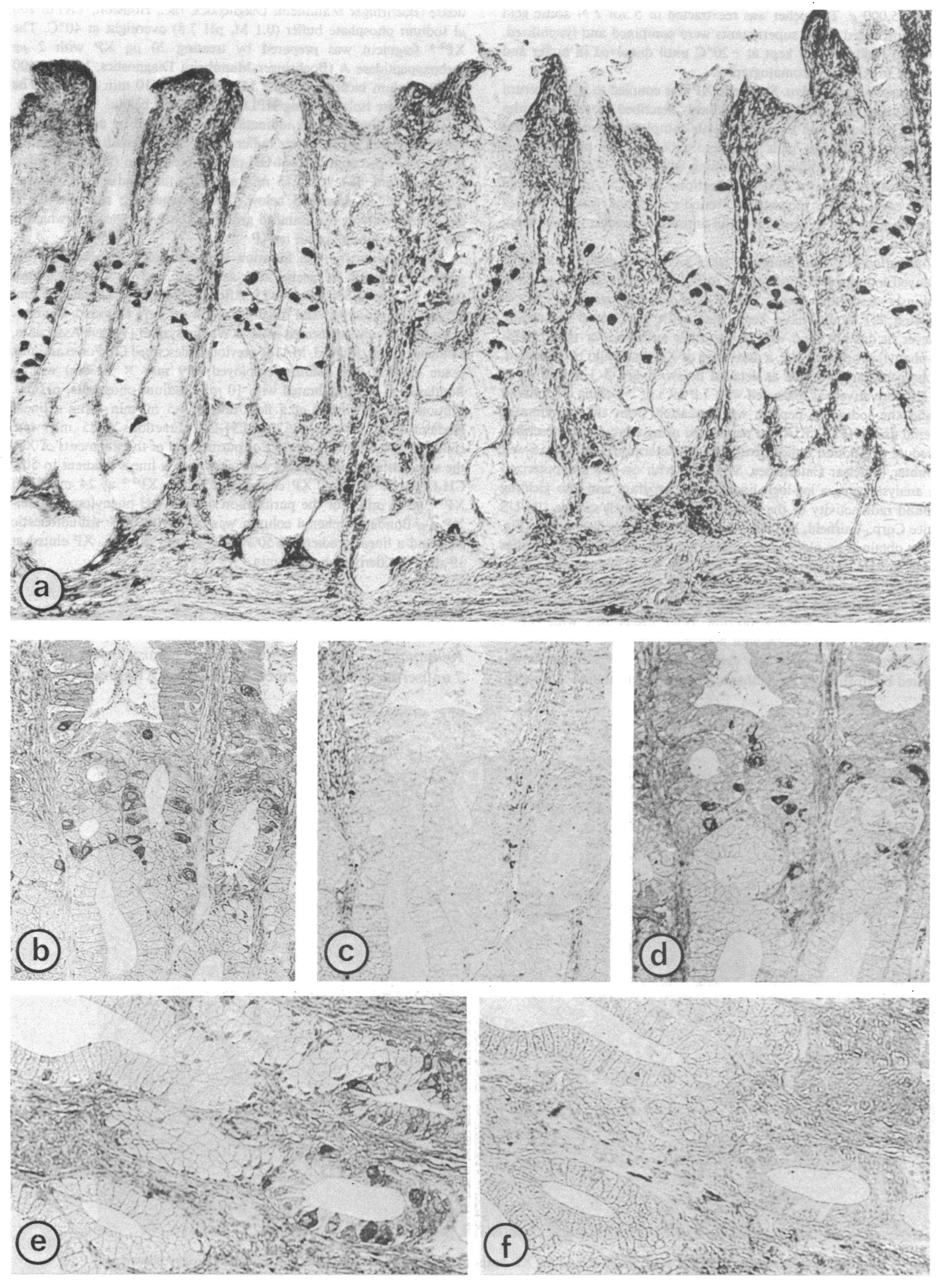




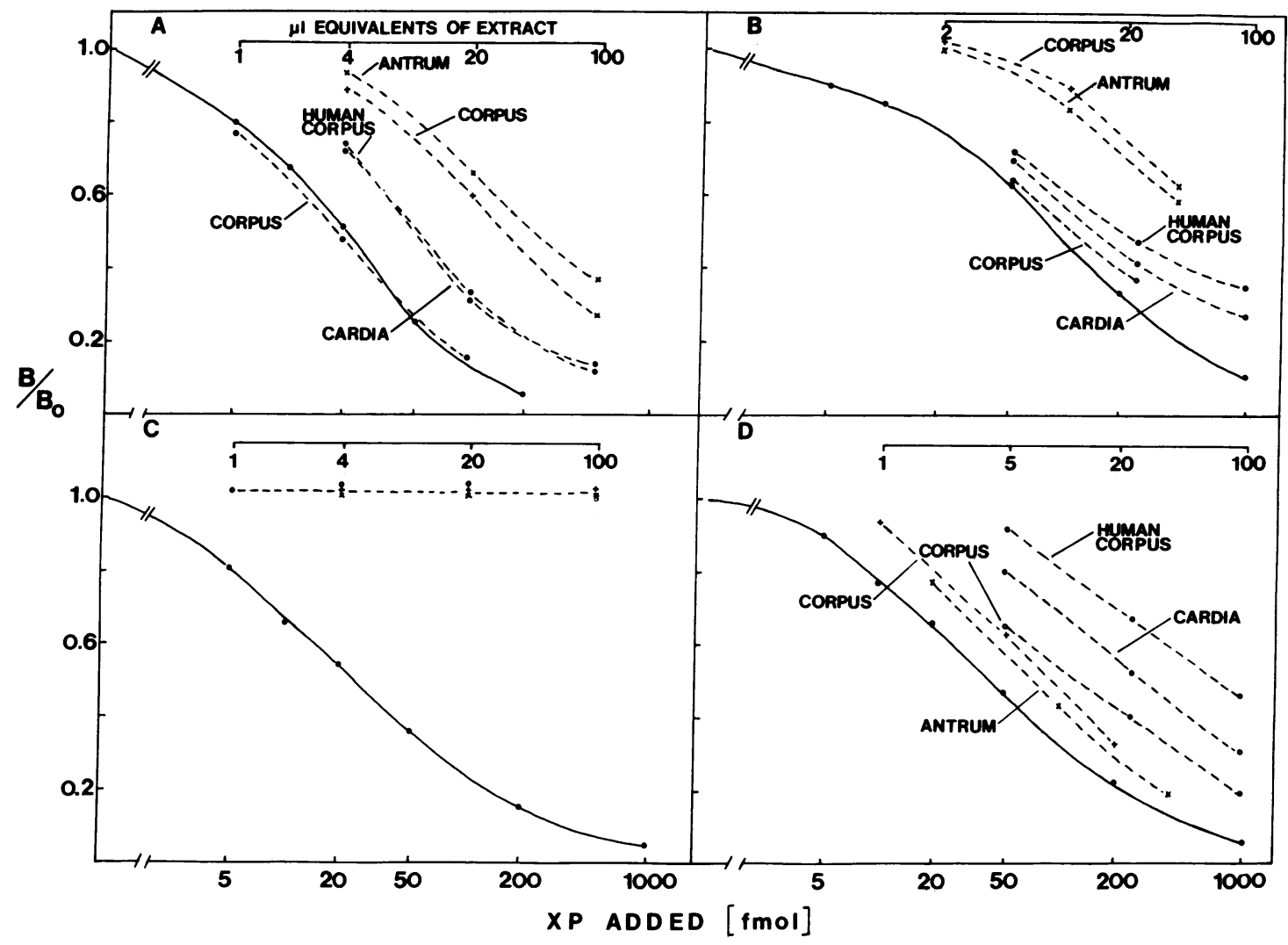

Figure 3. Comparison of inhibition curves produced by extracts of canine and human gastric tissues (dashed lines) to those by synthetic XP (solid lines and solid circles). (A) Antiserum Xen-6, 1:8,000; $(B)$ antiserum Xen-8, 1:60,000; $(C)$ antiserum Xen-5 1:500,000; and $(D)$ antiserum Xen-7, 1:75,000. (x), Acid acetone extracts as labeled; (O), acetic acid extracts as labeled. Unless indicated tissues are canine. Note that Xen-5, the N-terminal antiserum, showed no recognition for all extracts. cells of the open type in the middle layer of human and canine antral mucosa (Figs. 1 and 2). Preincubation of the antiserum with XP abolished the reaction, while pretreatment with gastrin had no effect when tested on adjacent semithin sections (Fig. $2 c$ and $d$ ). Preabsorption with the other peptides mentioned in Methods also did not abolish the immunohistochemical reaction (not shown). Nonimmune sera gave no reaction. Adjacent semithin sections of the canine antrum showed again a positive immunohistochemical reaction with the antiserum towards XP (Fig. $2 e$ ) and a negative reaction with an antiserum towards NT (Neu-6) (Fig. $2 f$ ). In contrast, canine ileum stained positively for NT and gave a negative reaction for the presence of XP (not shown).

XP-specific immunohistochemical staining could only be demonstrated in the antrum, not in the body of the stomach. In addition to Xen-7, a positive staining was also obtained with the Xen-6 antiserum; this reaction, however, was not abolished by preabsorption with XP.

Characteristics of the RIA. The four antisera displayed classical dose-response curves in the RIA, giving $50 \%$ displace- ment values which were between 15 and 85 fmol of XP (Fig. $3 A-D)$.

Specificities of the antisera to XP. Cross-reactivity estimates in the RIA for a number of peptides related to XP with the four antisera are given in Table I. First, note that all of the antisera differed in ability to recognize these substances. Xen6 appeared to be directed mostly towards the $C$-terminal region of XP, cross-reacting $100 \%$ with the $X^{2-8}$ fragment and $<0.01 \%$ with the $\mathrm{XP}^{1-6}$ fragment. Xen-8 was also primarily C-terminal-directed, cross-reacting $25 \%$ with $\mathrm{XP}^{2-8}$. Xen-5, on the other hand, displayed an $\mathrm{N}$-terminal specificity, reacting $15 \%$ with the $X^{1-6}$ and only $0.04 \%$ with $X^{2-8}$. Although Xen-7 required both ends of XP for strong recognition, the C-terminal region was most important for binding. With the exception of Xen-5, all of the antisera displayed partial recognition of NT, cross-reacting from $0.13 \%$ (Xen-7) to $8 \%$ (Xen-6). However, since NT is absent from the stomach, this did not present a major problem.

Behavior of gastric extracts in the RIA. Canine gastric extracts gave dose-response relationships in the RIA that were
Figure 2. Immunohistochemistry of XP in canine gastric antral mucosa. (a) XP antiserum Xen-7 (diluted 1:2,000) and the PAP technique revealed numerous epithelial cells in the middle layer of the mucosa in a paraffin section $(\times 100) .(b),(c)$, and $(d)$ Three adjacent semithin sections incubated with antiserum Xen-7 (diluted 1:500).
The antiserum was preabsorbed for $48 \mathrm{~h}$ with buffer $(b)$, with XP (c), and with gastrin $(d)(\times 800)$. $(e)$ and $(f)$ Two adjacent semithin sections. The XP antiserum Xen-7 showed a strong reaction with endocrine cells $(e)$. The NT antiserum Neu-6 $(1: 1,000)$ gave no reaction $(f) .(\times 800$. 


\begin{tabular}{|c|c|c|c|c|}
\hline \multirow[b]{2}{*}{ Peptide } & \multicolumn{4}{|c|}{ Immunoreactivity* } \\
\hline & Xen-5 & Xen-7 & Xen-8 & Xen-6 \\
\hline$\langle$ Glu-Gly-Lys-Arg-Pro-Trp-Ile-Leu-OH (XP) & 100 & 100 & 100 & 100 \\
\hline 〈Glu-Gly-Lys-Arg-Pro-Trp-OH & 15 & $<0.01$ & $<0.01$ & $<0.01$ \\
\hline H-Gly-Lys-Arg-Pro-Trp-Ile-Leu-OH & 0.04 & 0.13 & 25 & 100 \\
\hline H-Ile-Leu-OH & $<0.01$ & $<0.01$ & $<0.01$ & $<0.01$ \\
\hline H-Tyr-Ile-Leu-OH & $<0.01$ & $<0.01$ & $<0.01$ & $<0.01$ \\
\hline H-Pro-Tyr-Ile-Leu-OH & $<0.01$ & $<0.01$ & $<0.01$ & $<0.01$ \\
\hline H-Arg-Pro-Tyr-Ile-Leu-OH & $<0.05$ & $<0.01$ & $<0.72$ & $<0.06$ \\
\hline H-Arg-Arg-Pro-Tyr-Ile-Leu-OH & $<0.1$ & $<0.1$ & 1.1 & 0.4 \\
\hline 〈Glu-Leu-Tyr-Glu-Asn-Lys-Pro-Arg-Arg-Pro-Tyr-Ile-Leu-OH (NT) & $<0.05$ & 0.13 & 2 & 8 \\
\hline 〈Glu-Leu-Tyr-Glu-Asn-Lys-Pro-Arg-Arg-Pro-Tyr-Ile-OH & $<0.01$ & $<0.01$ & $<0.01$ & 0.3 \\
\hline 〈Glu-Leu-Tyr-Glu-Asn-Lys-Pro-Arg-Arg-Pro-Tyr-OH & $<0.01$ & $<0.01$ & $<0.01$ & $<0.01$ \\
\hline H-Lys-Asn-Pro-Tyr-Ile-Leu-OH & $<0.01$ & $<0.01$ & $<0.01$ & $<0.01$ \\
\hline
\end{tabular}

* As determined by the amount of peptide needed to inhibit by $50 \%$ the binding observed in the RIA at the antiserum dilutions used in Fig. 5 .

almost parallel to those for XP (Fig. $3 A, B$, and $D$ ), except with the N-terminal-directed antiserum Xen-5 which showed no recognition (Fig. $3 C$ ). As shown in Table II, the relative measurements of immunoreactive XP (iXP) depended upon the antiserum used, ranging from $100 \%$ (antiserum Xen-6) to $<1 \%$ (antiserum Xen-5). It appeared that the more C-terminal directed the antiserum, the higher was the measurement obtained. Since antiserum Xen-6 gave the highest measurements, it was used in further studies.

Extraction and distribution. The concentrations of iXP (antiserum Xen-6) and immunoreactive NT (iNT) (N-terminal antiserum TG-1 and C-terminal antiserum HC-8) in extracts of various canine gastrointestinal tissues are given in Table III. Using both the acetic acid extraction procedure (Table III, procedure $A$ ) and the acid/acetone extraction procedure (Table III, procedure B), the highest levels of iXP were measured in gastric tissues. After correction for cross-reacting NT, XPrelated material was detected at low levels in the pancreas and duodenum but found to be absent from the jejunoileum and

Table II. Relative Measurements of iXP in Acetic Acid and Acid/Acetone Extracts of Canine and Human Gastric Tissues

\begin{tabular}{|c|c|c|c|c|}
\hline \multirow[b]{2}{*}{ Extract of gastric tissue } & \multicolumn{4}{|c|}{ iXP as percentage of measure with Xen-6* } \\
\hline & Xen-6 & Xen-8 & Xen-7 & Xen-5 \\
\hline \multicolumn{5}{|l|}{ Acetic acid extracts } \\
\hline \multicolumn{5}{|l|}{ Canine } \\
\hline Cardia & 100 & 82 & 19 & $<1$ \\
\hline Corpus & 100 & 39 & 17 & $<1$ \\
\hline Antrum & 100 & 54 & 8 & $<1$ \\
\hline \multicolumn{5}{|l|}{ Human } \\
\hline Corpus & 100 & 78 & 10 & $<1$ \\
\hline \multicolumn{5}{|c|}{ Acid/Acetone extracts } \\
\hline \multicolumn{5}{|l|}{ Canine } \\
\hline Corpus & 100 & 37 & 50 & $<1$ \\
\hline Antrum & 100 & 30 & 42 & $<1$ \\
\hline
\end{tabular}

* Average relative measurement determined in the RIA using each antiserum as shown and expressed as percentage of that determined with antiserum Xen-6, $n=2-4$. Note that the antisera are listed in the order of most C-terminal (left) to most N-terminal (right). colon. In contrast, NT-related peptide(s) were found primarily in the jejunoileum. Although gastric extracts registered in the C-terminal-directed assay for NT, no recognition was obtained with the N-terminal antiserum. This indicated that NT was absent from the stomach.

Extraction with acetic acid gave a higher level of iXP and iNT in stomach than did extraction with acid/acetone, suggesting that some of the peptides were more soluble in aqueous acid. This was not the case for iNT extracted from jejunoileum, which gave higher measurements using acid/acetone.

The results in Table III also show that more iXP was found in the mucosal portion (90-98\% of total) than in the muscular layer of the stomach (2-10\% of total). Concentrations of iXP in human stomach were found to be similar to those in dog, and the activity was also localized to the mucosa (data not shown).

Gel chromatography. Fig. 4 shows the profiles of iXP (antiserum Xen-6) and iNT (antiserum HC-8) obtained when an extract of dog stomach was subjected to chromatography on Sephadex G-25. Note that iXP and iNT separated from one another and that two peaks of iXP were obtained. The elution positions for the two forms of iXP were consistent, with one being about the same size as XP (peak II) and the other being larger (peak I). It was also shown that the chromatographic profile of iXP measured using antiserum Xen-7 was identical to that for antiserum Xen-6, except that the concentrations measured were $\sim 25$-fold lower (not shown).

Reverse-phase HPLC. Fig. $5 B$ shows the profiles of iXP and iNT obtained when an extract of dog antrum was subjected to reverse-phase HPLC on $\mu$-Bondapak C-18. Again, iNT and iXP were found to separate from one another, and multiple peaks of iXP were obtained, one of which (peak III) eluted in the region of synthetic XP. A similar profile of iXP was obtained for extracts of the gastric corpus (Fig. $5 \mathrm{~A}$ ). Cochromatography of peak III with added synthetic XP was also demonstrated in subsequent analyses (not shown).

In contrast to the results obtained with gastric tissues, extracts of canine ileum gave a single coincident peak of iNT and iXP, eluting at the retention time for synthetic NT (Fig. $5 C$ ). All of the iXP observed was attributable to the known cross-reaction of NT $(\sim 8 \%)$ with the antiserum towards XP. 
Table III. Distribution and Concentrations of iXP and iNT in Canine Gastrointestinal Tissues Extracted with $2 \mathrm{~N}$ Acetic Acid and Acid/Acetone

\begin{tabular}{|c|c|c|c|c|c|c|}
\hline \multirow[b]{2}{*}{ Tissue* } & \multicolumn{2}{|c|}{ iXP (Xen-6) } & \multicolumn{2}{|c|}{ iNT (TG-1) } & \multicolumn{2}{|c|}{ iNT (HC-8) } \\
\hline & A & B & A & B & A & B \\
\hline & $\mathrm{pmol} / \mathrm{g}$ & $\mathrm{pmol} / \mathrm{g}$ & $\mathrm{pmol} / \mathrm{g}$ & $\mathrm{pmol} / \mathrm{g}$ & $\mathrm{pmol} / \mathrm{g}$ & $\mathrm{pmol} / \mathrm{g}$ \\
\hline Stomach & $203 \pm 22$ & $1.8 \pm 0.2$ & $<0.2$ & $<0.1$ & $56 \pm 10$ & $1.2 \pm 0.2$ \\
\hline Duodenum & $10 \pm 3$ & ND & $4 \pm 2$ & ND & $6 \pm 2$ & ND \\
\hline Pancreas & $1 \pm 0.2$ & ND & $<0.2$ & ND & $2 \pm 0.5$ & ND \\
\hline Jejunum & $<1$ & $<0.1$ & $96 \pm 15$ & 108 & $57 \pm 9$ & 115 \\
\hline Ileum & $<1$ & $<0.1$ & $221 \pm 24$ & 302 & $121 \pm 8$ & 307 \\
\hline Colon & $<0.5$ & ND & 1.3 & ND & 1.4 & ND \\
\hline \multicolumn{7}{|c|}{ Regions of stomach } \\
\hline \multicolumn{7}{|l|}{ Corpus } \\
\hline Mucosa & 270 & 2.6 & $<0.2$ & $<0.2$ & 157 & 2.7 \\
\hline Muscle & 26 & 0.2 & $<0.2$ & $<0.2$ & 11 & 0.2 \\
\hline \multicolumn{7}{|l|}{ Antrum } \\
\hline Mucosa & 157 & 2.9 & $<0.2$ & $<0.2$ & 77 & 3.2 \\
\hline Muscle & 3 & 0.2 & $<0.2$ & $<0.2$ & 1 & 0.2 \\
\hline \multicolumn{7}{|l|}{ Cardia } \\
\hline Mucosa & 190 & ND & $<0.2$ & $<0.2$ & 83 & ND \\
\hline Muscle & 5 & ND & $<0.2$ & $<0.2$ & 3 & ND \\
\hline
\end{tabular}

* Tissues were extracted with $2 \mathrm{~N}$ acetic acid (A) and acid/acetone (B) as stated in Methods, and lyophilized samples were assayed in the RIA. For iXP, the C-terminal-directed Xen-6 was employed. For iNT, HC-8, a C-terminal antiserum, and TG-1, an N-terminal antiserum, were employed. Given is the mean \pm SEM for $n=6$ or the mean for $n=2$. The measurements given for jejunum and ileum were corrected for $8 \%$ cross-reaction of NT in the XP-assay. ND, not determined.

\section{Discussion}

The major conclusions drawn from this study are the following: 1) XP-related peptides are present within epithelial cells of both canine and human gastric antral mucosa; 2) these peptides do not react with antisera towards NT; 3) whereas NT is located primarily in the ileum, iXP measured by RIA is present mainly in the upper gut; 4) canine gastric extracts contain both large and small molecular forms of iXP; 5) although one form of gastric iXP coelutes with synthetic XP during HPLC, its identity with XP cannot be considered proved; and 6) immunochemical results suggest that these canine XP-related peptides are most similar to XP in their C-terminal regions.

Thus, counterparts to XP, a peptide originally found in amphibian skin, appeared within mammalian gastric epithelial cells where they may act as messengers. This finding contradicts recent work reported by Goedert et al. (11), who concluded

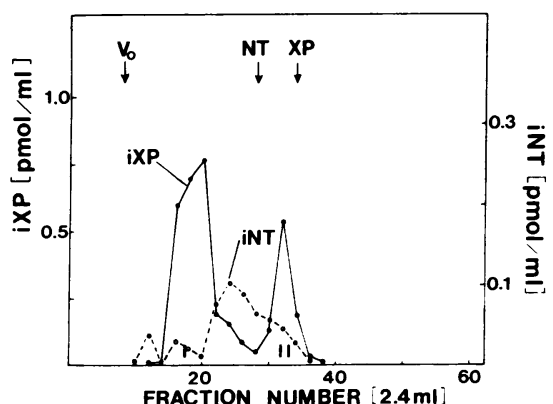

Figure 4. Gel chromatography performed on an acetic acid extract of canine gastric tissue on Sephadex G-25. For details see text. Sample contained $0.1 \mathrm{~g}$ of equal parts of cardia, corpus, and antrum in 1.5 $\mathrm{ml} 5 \%$ acetic acid. Antisera Xen-6 and HC-8 were used for measurements. Recovery was $\sim 85 \%$. $\mathrm{V}_{0}$, void volume. that the gene for XP was lost during the evolution of mammals and that the observed biologic effects of XP in these species are of no physiologic significance. The failure of that group to detect XP-related peptides in mammals was most likely due to the nature of the antisera they employed which, although not well characterized, were likely to be N-terminal-directed.

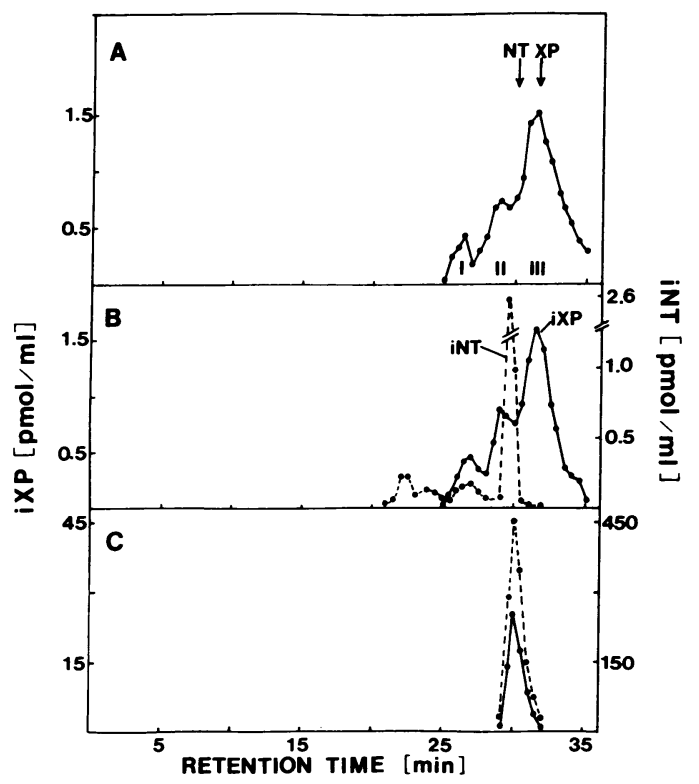

Figure 5. HPLC of acetic acid extracts of canine tissues on $\mu$ Bondapak C-18. For details see text. $(A)$ Gastric corpus; $(B)$ gastric antrum; and $(C)$ ileum. Note that $A$ and $B$ gave similar profiles of iXP eluting near to the standard XP. In contrast, $C$ gave only NT, which cross-reacted in the iXP assay. Antisera Xen-6 and HC-8 were used for measurements. Recoveries were $>90 \%$. 
The results in the present study indicate clearly that three antisera towards the C-terminal region of XP recognized canine iXP in the RIA, while one N-terminal-directed antiserum did not, thus suggesting that mammalian and amphibian iXP differ slightly in structure.

We contend that neither the immunohistochemical staining nor the RIA measurements for iXP in gastric tissue can be attributable to a cross-reaction of NT with the antisera towards XP. Although a slight cross-reaction was possible, NT was shown to be absent from the canine and human stomach. This is evidenced by the fact that an antiserum towards NT, which was shown to stain N-cells of the ileum, was unable to stain the XP-positive gastric cells. Furthermore, preincubation with NT did not abolish the staining obtained in stomach with antisera towards XP. In addition, extracts of gastric tissue did not react with an $\mathrm{N}$-terminal-directed antiserum towards NT. Finally, although a C-terminal antiserum towards NT did recognize gastric material, these substance(s) separated from gastric iXP during chromatography.

Since the specificity expressed by an antiserum can differ in immunohistochemistry and RIA, we cannot equate the activities detected here by these two methods. The fact that both procedures gave positive results does, however, greatly strengthen the case for the presence of XP-related material in the stomach and constitutes convincing evidence that at least some of these peptides are localized within epithelial cells of the antrum.

The use, however, of both RIA and immunohistochemistry has also given rise to certain discrepancies. Regarding the distribution of $\mathrm{iXP}$, we could not stain XP-immunoreactive cells in the body of the stomach, whereas RIA gave concentrations of iXP in the body that were similar to those found in the antrum. One possible explanation is that the variant of XP present in the body of the stomach, although extractable, cannot be fixed and therefore, cannot be demonstrated by the immunohistochemical reagents. We also found that one of the antisera, Xen-6, gave the highest measurements in RIA, but its immunohistochemical staining could not be abolished by preabsorption with XP. Apparently, different antibodies are required to recognize formaldehyde-fixed iXP than are needed for optimal binding of the radioactively labeled XP tracer. This is not surprising, since the XP is derivatized at different positions in the molecule for these two techniques. It should also be recognized that antisera can express different specificities depending upon the dilutions used. Thus, the same antiserum, when used for immunohistochemistry, could recognize different members of a peptide family than those detected by RIA.

Nevertheless, our study has given firm evidence for the presence of multiple XP-related substances in the mammalian stomach. Furthermore, the immunochemical results suggest that these peptides bear a strong resemblance to the C-terminal portion of XP and differ at their N-termini. Since the pharmacologic abilities of NT- and XP-related peptides, in general, depend most highly upon groups located within the five Cterminal residues, the similarity in this region suggests that these gastric XP-related substances may possess biologic activity.

Regarding possible biologic function(s) for gastric iXP, it should be noted that synthetic XP given intravenously to dogs potently inhibits gastrin-driven gastric acid secretion (12), stimulates exocrine pancreatic secretion (13), increases blood flow to the adrenals, pancreas, and ileum (12), and can stimulate the release of pancreatic polypeptide, insulin, and glucagon (12). XP has also been shown to release gastrin, insulin, and glucagon $(14,15)$ and to alter vascular permeability to protein (2). It will be interesting to see if gastric iXPs possess similar activities and if they can be released into gastric blood or luminal fluid. Further investigations concerning the biologic capabilities of XP-related peptides in mammals certainly seem warranted at this time.

\section{Acknowledgment}

Excellent technical help was provided by Mrs. E. Weilguni, Mrs. Carol Paradise, and Mrs. Rebecca Salmonsen. We also thank Mrs. Carolyn Rassias for assistance in preparing the manuscript.

This investigation was supported by grants from the Deutsche Forchungsgemeinschaft Fe 127/5-6, the Boehringer Ingelheim Fonds, Stiftung fur Medizinische Grundlagenforschung, and grants AM 28565 and AM 28557 from the National Institutes of Health.

\section{References}

1. Araki, K., S. Tachibana, M. Uchiyama, T. Nakajima, and T. Yasuhara. 1975. Isolation and structure of a new active peptide xenopsin on rat stomach strip and some biogenic amines in the skin of Xenopus laevis. Chem. Pharm. Bull. (Tokyo). 23:3132-3140.

2. Araki, K., S. Tachibana, Y. Kato, and T. Tajima. 1979. Comparative studies of xenopsin and neurotensin on some biological activities. Yakugaku Zasshi. 99:466-470.

3. Carraway, R. E., S. E. Ruane, G. E. Feurle, and S. Taylor. 1982. Amphibian neurotensin (NT) is not xenopsin (XP): dual presence of NT-like and XP-like peptides in various amphibia. Endocrinology. 110:1094-1101.

4. Hackenthal, E., J. Metz, K. Poulsen, E. Rix, and R. Taugner. 1980. Renin in the uterus of non-pregnant mice: immunocytochemical, ultrastructural and biochemical studies. Histochemistry. 66:229-238.

5. Rix, E., E. Hackenthal, U. Hilgenfeldt, and R. Taugner. 1981. Neuropeptides in the pineal gland. Histochemistry. 72:33-38.

6. Helmstaedter, V., C. Taugner, G. E. Feurle, and W. G. Forssmann. 1977. Localization of neurotensin-immunoreactive cells in the small intestine of man and various mammals. Histochemistry. 53:35-41.

7. Carraway, R. E., and S. E. Leeman. 1976. Characterization of radioimmunoassayable neurotensin in the rat. Its differential distribution in the central nervous system, small intestine, and stomach. J. Biol. Chem. 251:7045-7052.

8. Reichlin, M., J. J. Schnure, and V. K. Vance. 1968. Induction of antibodies to porcine ACTH in rabbits with nonsteroidogenic polymers of BSA and ACTH. Proc. Soc. Exp. Biol. Med. 128:347350.

9. Carraway, R. E., and S. E. Leeman. 1976. Radioimmunoassay for neurotensin, a hypothalamic peptide. J. Biol. Chem. 251:70357044.

10. Hammer, R. A., S. E. Leeman, R. E. Carraway, and R. H. Williams. 1980. Isolation of human intestinal neurotensin. J. Biol. Chem. 1257:2476-2480.

11. Goedert, M., N. Sturmey, B. J. Williams, and P. C. Emson. 1984. The comparative distribution of xenopsin- and neurotensin-like immunoreactivity in xenopsin laevis and rat tissues. Brain Res. 308: 273-280.

12. Zinner, M. J., F. Kasher, I. M. Modlin, and B. M. Jaffe. 1982. Effect of xenopsin on blood flow, hormone release, and acid secretion. Am. J. Physiol. 243:G195-G199.

13. Feurle, G. E., I. Baća, W. Knauf, A. Schwab, T. Araki, and R. E. Carraway. 1982. Xenopsin stimulates exocrine pancreatic secretion in the dog. Experientia (Basel). 38:679-680.

14. Ishida, T., K. Kawamura, A. Goto, Y. Nishina, J. Takahara, S. Yamamoto, K. Kawanishi, and T. Ofjui. 1976. Comparison studies of neurotensin and xenopsin upon pancreatic secretion in the dog. Metab. Clin. Exp. 25(Suppl. 1):1467-1468.

15. Kawanishi, K., A. Goto, T. Ishida, K. Kawamura, Y. Nishina, S. Machida, S. Yamamoto, and T. Ofuji. 1978. The effects of xenopsin on endocrine pancreas and gastric antrum in dogs. Horm. Metab. Res. 10:283-286. 